\title{
La Sagrada Escritura «una cum Sacra Traditione» ante el reto de la 'sola Scriptura'
}

\author{
The Sacred Scripture «una cum Sacra Traditione» \\ in the Face of the 'sola Scriptura' Challenge
}

\section{Vicente BALAGUER}

Universidad de Navarra. Facultad de Teología

Pamplona. España

vbalaguer@unav.es

Resumen: El principio luterano de la sola Scriptura como fuente de revelación ha suscitado en los católicos la idea de un rechazo a la Tradición como fuente de conocimiento de la revelación. Sin embargo, un repaso breve a cómo entendió Lutero la Sagrada Escritura y al modo con que la Iglesia católica afrontó la Reforma en los concilios de Trento y del Vaticano II, muestra los aspectos positivos de este reto de la Reforma. La fórmula de Dei Verbum donde la Sagrada Escritura «una cum Sacra Traditione» constituye la regla de fe y la fuerza y el vigor de la Iglesia hace justicia a la tradición católica y a uno de los principios de la Reforma.

Palabras clave: Sagrada Escritura, Tradición, Lutero, Trento, Dei Verbum.
Abstract: The Lutheran principle of sola Scriptura as a source of Revelation generated among the Catholics the tendency to reject Tradition as a means of knowing the Revelation. However, a brief review of the way Luther understands the Sacred Scripture and how the Catholic Church confronted the Reformation in the Councils of Trent and Vatican II can show the positive aspects of the challenge posed by the Reformation. Dei Verbum's formula, according to which the Sacred Scripture, «una cum Sacra Traditione», constitutes the rule of faith and the Church's power and vigor, gives due recognition both to the Catholic point of view and to one of the Reformation's main tenets.

Keywords: Sacred Scripture, Tradition, Luther, Trent, Dei Verbum. 
T radicionalmente se ha caracterizado a la teología de la Reforma por el principio de que la revelación se contenía en la sola Scriptura, en tanto que la teología católica entendía que se contenía también la Tradición, y con ella el Magisterio. Los tintes polémicos de cuatro siglos desaparecieron sin embargo en los años del Concilio Vaticano II. Significativamente, en 1963, la Comisión Fe y Constitución del Consejo Mundial de las Iglesias reunido en Montreal declaraba: «Podemos decir que somos cristianos por la tradición del Evangelio (la paradosis del kerygma) atestiguado en la Escritura, transmitido en la Iglesia y por la Iglesia a través de la Escritura. La Tradición, entendida en este sentido se actualiza en la predicación de la Palabra, en la administración de los sacramentos, en el culto, en la catequesis, en la teología cristiana y en la misión y testimonio que se da de Cristo en la vida de la Iglesia» ${ }^{1}$.

Por parte católica, el documento del Vaticano II sobre la revelación, que había iniciado su andadura con un esquema titulado De fontibus revelationis (1962), proponiendo Escritura y Tradición como dos fuentes de la revelación, acabó en la Constitución Dogmática Dei Verbum (1965), donde la fuente (scaturigo) era sólo una y los modos de transmisión dos: la Escritura (locutio Dei) y la Tradición que transmitía la Palabra de Dios (verbum Dei), pero que en ningún momento recibía ese nombre (cfr. DV 9). Además, en el capítulo dedicado a la vida de la Iglesia, el valor rector de la Escritura quedaba expresamente señalado: como regla de fe y como alma de la Escritura. Pero señalaba también que la Escritura era inseparable de la Tradición. La Iglesia, decía, DV 21, Divinas Scripturas... una cum Sacra Traditione semper ut supremam fidei suae regulam habuit et habet, y poco después: Sacra Theologia in verbo Dei scripto, una cum Sacra Traditione, tamquam in perenni fundamento innititur, in eoque ipsa firmissime roboratur semperque iuvenescit, omnem veritatem in mysterio Christi conditam sub lumine fidei perscrutando (DV 24).

No es extraño por esto que en el campo de la exégesis la diferencia de confesión religiosa no sea muy relevante para los resultados, ni que en el diálogo ecuménico cuando se trata de cuestiones de interpretación de la Escritu$\mathrm{ra}$, el entendimiento en este punto parezca casi completo ${ }^{2}$. Aunque es indudable que el horizonte ecuménico influyó en las formulaciones del Vaticano II,

${ }^{1}$ Vischer, L. (ed.), Textos y documentos de la Comisión «Fe y Constitución» (1910-1968), Madrid: BAC, 1968.

${ }^{2}$ Las diferencias permanecen en el «acento» y los «matices»: SKILlRUd, H. C., STAFFORD, J. F. y Martensen, D. F. (eds.), Scripture and Tradition: Lutherans and Catholics in Dialogue IX, Minneapolis: Augsburg, 1995. 
probablemente es más cierto que tales formulaciones se deben a la misma reflexión de la teología católica sobre sus fundamentos, eso sí, ante los retos planteados también por la teología de la Palabra de Dios de la Reforma. El primer párrafo de Dei Verbum, señalado muchas veces como una de las páginas más bellas del Concilio y verdadera puerta de entrada de los restantes documentos, quiere hacer justicia a algunos de estos aspectos: a la primacía de la Palabra de Dios, un reto planteado desde la Reforma, a los fundamentos bíblicos del mensaje que la Iglesia proclama a los hombres y, finalmente, a la tradición católica que le precede. El texto dice:

$\ll$ El Santo Concilio, escuchando religiosamente la Palabra de Dios y proclamándola con confianza, hace suya la frase de S. Juan, que dice: "Os anunciamos la vida eterna, que estaba en el Padre y se nos manifestó: lo que hemos visto y oído os lo anunciamos a vosotros, a fin de que viváis también en comunión con nosotros, y esta comunión nuestra sea con el Padre y con su Hijo Jesucristo" (1 Jn 1,2-3). Por tanto, siguiendo las huellas de los Concilios Tridentino y Vaticano I, se propone exponer la doctrina genuina sobre la divina revelación y sobre su transmisión, para que todo el mundo, oyendo, crea el anuncio de salvación; creyendo, espere; y esperando, ame» (DV1) ${ }^{3}$.

Algunas notas sobre el reto que supuso la posición de Lutero, y más tarde de la Reforma, a la teología y la exégesis católicas pueden, por eso, iluminar el modo con que la exégesis católica se plantea hoy en día.

\section{LA REFORMA Y LA INTERPRETACIÓN DE LA ESCRITURA}

En el marco de toda la historia de la teología, la teología de la Reforma tiene la marca de lo existencial: no es un discurso de la fe a la búsqueda de su inteligencia, sino un discurso en búsqueda de la certeza de la salvación. Es verdad que Lutero era un exegeta más que un teólogo y que el protestantismo, ya desde Melanchthon, se organizó de una manera sistemática, de modo que

\footnotetext{
${ }^{3}$ La esencia plena de la Iglesia, está resumida en el gesto de escuchar, el único gesto del que puede derivar su anuncio. La Iglesia se pone bajo la autoridad de la Palabra de Dios. Si la escucha es religiose, la proclamación es fidenter; cfr. RATZINGER, J., «Kommentar zur Dogmatischen Konstitution über die göttliche Offenbarung. I Kapitel», en Vorglimler, H. (ed.), Das Zweite Vatikanische Konzil. Teil II (Lexikon für Theologie und Kirche), Freiburg-Basel-Wien: Herder, 1967, 504.
} 
unos siglos más tarde la teología protestante no se diferenciará mucho de la escolástica católica incluso con formas de neoaristotelismo no confesado ${ }^{4}$. Sin embargo, esta teología - muy variada en las formulaciones, especialmente tras el impacto del historicismo en el XIX- no se apartará de las primeras confesiones de la Iglesia Luterana Evangélica ${ }^{5}$, ya desde el Liber Concordiae de 1580: sola Scriptura iudex, norma et regula agnoscitur. Ahora bien, esta fórmula no es una especie de logion solitario: está enraizada en la vida y en el pensamiento más amplio de Lutero.

\subsection{Martín Lutero}

Quizás por el carácter existencial apenas mencionado, los principios relativos a la interpretación de la Escritura de Lutero parten de convicciones que suponen a la vez rechazos ${ }^{6}$. La convicción del reformador, que los autores retrotraen a 1513 , es la justificación por la sola fe, y no por las obras humanas:

«La justicia de Dios no se adquiere por medio de actos frecuentemente repetidos, como enseñó Aristóteles, sino que es ofrecida por la fe (Rm 1,17; 10,10). De todas formas, querría que las palabras "sin obras" se entendieran de la siguiente manera: no que el justo no haga nada, sino que sus obras no lo hacen justo, es más bien la justicia la que hace las

${ }^{4}$ Cfr. Lacoste, J.-Y., «Teología», en IDEM (ed.), Diccionario Crítico de Teología, Madrid: Akal, 2007, 1181-1187.

5 Cfr. BüHler, P., «Confesiones de fe. B: Tradición protestante», en Lacoste, J.-Y. (ed.), Diccionario Crítico de Teología, 287-288. Para el carácter apologético que toma la teología en torno a la noción de sola Scriptura, pueden repasarse los textos apologéticos de Martin Chemnitz (singularmente, el Examinis Concilii Tridentini), discípulo más de Mellanchton que de Lutero y uno de los redactores y organizadores del Liber Concordiae. Resulta particularmente ilustrativo a este respecto: MERricK, J. R. A., «Sola Scriptura and the regula fidei: The Reformation scripture principle and early oral tradition in Martin Chemnitz, Examination of the Council of Trent», Scottish fournal of Theology 63/3 (2010) 253-271.

${ }^{6}$ Me guío aquí por algunas exposiciones del pensamiento de Lutero en el diálogo interreligioso. Suelen convocar los mismos textos de Lutero: LAZARETH, W. H., «Luther's 'Sola Scriptura': Traditions of the Gospel for Norming Christian Righteousness», en NeuHaus, R. J. (ed.), Biblical Interpretation in Crisis: the Ratzinger Conference on Bible and Cburch, Grand Rapids, Mich.: Eerdmans, 1989, 50-73 (luterano, sobrio, sin excesivos adjetivos; el más claro, de quien depende en gran parte mi resumen); ElowsKY, J., «Scripture and Tradition in an Evangelical Context», Concordia fournal, Winter 2016, 41-62 (con una lectura un poco deficiente de Trento y en general de la posición católica, aunque cite a buenos teólogos católicos); O'CALLAGHAN, P., «Sola Scriptura o tota Scriptura? Una riflessione sul principio formale della teologia protestante», en TÁBET, $M$. (ed.), La Sacra Scrittura anima della teologia, Città del Vaticano: Libreria Editrice Vaticana, 1999, 147-168; y CoRsani, B., Lutero e la Biblia, Brescia: Queriniana, 2001 (posición católica). 
obras. Porque la gracia y la fe se infunden sin nuestras obras. Cuando se nos han concedido, las obras les siguen ${ }^{7}$.

La mención a Aristóteles en este texto apunta ya a uno de los rechazos: Lutero rechaza todo lo que puede desdibujar sus convicciones y el reformador veía en el filósofo y en santo Tomás de Aquino los representantes de una escolástica que, a su juicio, impedía toda reforma: «Virtualmente, la entera Ética de Aristóteles es el peor enemigo de la gracia... En breve, todo Aristóteles es para la teología, lo que es la oscuridad para la luz» ${ }^{8}$. Pero este rechazo frontal al modelo aristotélico y también al tomista se une, y esto es lo importante, al rechazo a la razón: la razón está corrompida por el pecado y, en consecuencia, «es imposible armonizar fe y razón... Hay que abandonar la razón, sin conocerla siquiera, aniquilarla del todo; de lo contrario no se puede entrar en el cielo». En orden a la salvación, la razón debe desaparecer ante la fe, como la teología y la vida entera debe ser reformada desde la Sagrada Escritura, o, más bien, desde la Palabra de Dios que se nos ofrece en la Sagrada Escritura: «Creo simplemente que es imposible reformar la Iglesia a no ser que el derecho canónico, la teología escolástica, la filosofía, la lógica, tal como ahora se enseñan ahora, se enraícen profundamente... de modo que el puro estudio de la Biblia y de los padres de la Iglesia sean restaurados»?

De ahí el lugar que concede a la Palabra de Dios: «La Palabra de Dios es el comienzo, la fundación, la roca, que debe cimentar todas las obras, las palabras y los pensamientos de los hombres». La Palabra de Dios es aquello en quien Lutero confía cuando desconfía de otras mediaciones autoritativas. Así lo muestra en las palabras de su testimonio en la Dieta de Worms (1521), cuando se declara cautivo de la Palabra de Dios: «A no ser que sea convencido por el testimonio de la Escritura o por una razón clara (ya que no confío ni en el papa ni en los concilios ellos solos, ya que es bien conocido que han errado a menudo y que se han contradicho a sí mismos), estoy vinculado por las Escrituras que he mencionado y mi conciencia está cautiva por la Palabra de Dios... No puedo obrar de otra manera ${ }^{10}$.

El rechazo a la autoridad del papa y de los concilios es obviamente mucho más fuerte cuando se trata de las tradiciones, de las consuetudines ecclesiae -un

\footnotetext{
7 Probationes conclusionum quae in capitulo Heidelbergensi disputatae sunt, 25 (1518): WA 1, 364.

${ }^{8}$ Disputatio contra scholasticam theologiam (1517): WA 1, 221-228, Proposiciones 41.50.

${ }^{9}$ Cfr. Asterisci Lutheri adversus obeliscus Erkis (1518): WA 1, 281-314.

${ }^{10}$ Dictio D. Martin Lutheri coram Caesari Carolo et principibus: WA 7, 838.
} 
conjunto en Lutero un tanto heterogéneo, desde la confesión secreta al precepto dominical o a las bulas- que según el reformador determinaban en exceso la vida de la Iglesia y que habían dado lugar a abusos que se justificaban invocando la tradición. Si no puede confiar en las mediaciones humanas, sí puede hacerlo en la Palabra de Dios. En realidad, en Lutero Palabra de Dios y Escritura ni se identifican sin más, ni se pueden separar. La Palabra de Dios sólo puede ser una palabra viva, no una palabra escrita. Por eso, Cristo no escribió nada, para que el Nuevo Testamento pudiera llegar a ser verdaderamente la Palabra de Dios viva ${ }^{11}$.

Ahora bien, con el rechazo de toda mediación interpretativa, queda solamente la Sagrada Escritura. Cómo interpretarla. En primer lugar, en su sentido literal. Se recuerda en ocasiones que al comienzo de su docencia Lutero practicó una exégesis alegórica; sin embargo, como él mismo dice, la abandonó tras su «conversión», al descubrir a Cristo en la carta a los Romanos ${ }^{12}$. Desde este momento, se atuvo al sentido literal, plano, de los escritos sagrados: la Escritura es suficientemente clara, por tanto, la Escritura sólo se corrige con la Escritura. Ahora bien, esto supone un principio general que no da razón de las interpretaciones particulares. Por eso, entre sus textos aparecen también algunos criterios que solucionan los problemas que puede plantear la cuestión de la Scriptura sui interpres: en concreto, qué textos interpretan a otros.

En primer lugar, la interpretación del Antiguo Testamento y el Nuevo. Él mismo señala que, también en este punto, el momento de su conversión fue definitivo: hasta su experiencia mística, dice, le «faltaba una distinción propia entre la Ley y el Evangelio. Consideraba que ambos eran lo mismo y que Cristo sólo se diferenciaba de Moisés en el tiempo y en la perfección. Cuando descubrí la diferencia entre la Ley y el Evangelio, en cuanto son dos cosas distintas, es cuando conseguí abrirme paso ${ }^{13}$. La Ley, Moisés, pertenece al tiempo anterior a la gracia del mismo modo que el hombre, antes de la gracia y sin la

${ }^{11}$ Cfr. Lazareth, W. H., «Luther's 'Sola Scriptura': Traditions of the Gospel for Norming Christian Righteousness», 60.

12 «Cuando era monje, era un maestro de la alegoría. Hacía alegoría de cualquier cosa. Pero sólo con la carta a los Romanos llegué a conocer un poco a Cristo... Jerónimo y Orígenes, que Dios les perdone, sólo nos han servido para hacernos buscar alegorías. En todo Orígenes no hay una Palabra de Cristo»; el texto es tardío, de 1532, y pertenece a las conversaciones de sobremesa (WA TR 1, 136). Sobre este cambio de dirección interpretativa del Nuevo Testamento, y de toda la tradición patrística, cfr. BoRI, P. C., L'interpretazione infinita. L'esegesi cristiana antica e le sue trasformazioni, Bologna: Il Mulino, 1987, 124-125.

${ }_{13}$ Tischreden: WA TR 5, 5553. 
gracia, pertenece al pecado. En ese descubrimiento, «me apareció de improviso el otro aspecto de la Escritura» ${ }^{14}$ : la dialéctica del pecado y la gracia que se manifestaba en los dos testamentos. El ejemplo más claro se ve en la interpretación de los Salmos: los Salmos, en la interpretación de Lutero, dibujan el alma del hombre en su necesidad de justificación, pero sólo en Cristo, como muestra Romanos, la justificación ofrece su cara verdadera. También el Antiguo Testamento tiene la claritas necesaria de la Escritura en sentido literal, pero la tiene cuando se interpreta a contrario, como el negativo respecto del positivo e interpretado al modo existencial.

Esta interpretación existencial es la que sostiene el conocido dictum: «was Christum treibet»: «Ésta es la piedra de toque con la que probar todos los libros: si conducen a Cristo (was Christum treibet) o no, ya que toda la Escritura muestra a Cristo... Lo que no enseña a Cristo no es siquiera apostólico, aunque lo enseñara san Pedro o san Pablo. Por otra parte, lo que predica a Cristo es apostólico, aunque lo enseñe Judas, Ana, Pilatos o Herodes» ${ }^{15}$; o con otra imagen: «las Escrituras son los pañales y el pesebre donde Cristo está envuelto y donde descansa». En el pesebre de la Escritura es donde debemos distinguir entre los pañales, inseparables de Cristo, y Cristo mismo, entre las palabras humanas y la Palabra de Dios ${ }^{16}$. Por tanto, es la lectura misma de la Escritura la que justifica la jerarquización de los libros, en cuanto expresión del Evangelio, tal como viene recogida en el Prefacio a los libros del Nuevo Testamento de 1522:

«Desde esto, se pueden juzgar todos los libros del Nuevo Testamento y decidir cuáles entre ellos son los mejores. El evangelio de san Juan y las Cartas de san Pablo, especialmente la de los Romanos, y la Primera de Pedro son el núcleo y la esencia de todos los libros... Pero la Carta de Santiago es realmente una carta de paja, comparada con ellos, ya que no se encuentra nada de la naturaleza del Evangelio en ella» ${ }^{17}$.

Obviamente, se podrían invocar probablemente mejores textos, pero el resumen puede explicar bien el aserto ante León $\mathrm{X}^{18}$ : La Sagrada Escritura es

\footnotetext{
14 BORI, P. C., L'interpretazione infinita, 122: WA 54, 156.

15 Vorrbede auff die Epistelm Sanct facobi und 7udas (1922): WA DB 7, 384.

16 Desde textos de Lutero, la imagen la desarrolla LazareTH, W. H., «Luther's 'Sola Scriptura': Traditions of the Gospel for Norming Christian Righteousness», 64s.

17 Vorrede wilchs die rechten und Edlisteu bucher des newen testaments sind: WA DB 6,10.

18 M. Lutheri per Bullam Leonis X novissimam damnatorum: WA 7, 97.
} 
per se certissima, apertissima, sui ipsius interpres ómnium omnia probans iudincans et illuminans.

\subsection{La teología evangélica}

Aunque, como apenas se acaba de ver, frente al planteamiento escolástico, Lutero invocaba para la reforma las enseñanzas de los Padres, y en el $L i$ ber Concordiae, junto con la Confessio Augustana, se incluían profesiones de fe como la de los apóstoles, la nicena, etc. ${ }^{19}$, la sola Scriptura permanecía como principio inamovible: la Escritura sólo se corrige con la Escritura. Este principio sigue siendo central en la enseñanza de Calvino. Aunque su teología es más contemplativa, y mantiene un doble conocimiento de Dios, por la creación y por la palabra, el punto de partida no pueden ser los elementos de este mundo sino el Evangelio. En este sentido, una afirmación de la Confesión de la Rochelle (1559) ofrece un sumario que es estrictamente fiel a Calvino: «Dios se manifiesta como tal a los hombres, primero por sus obras, tanto por la creación como por su conservación y guía. En segundo lugar y más claramente, por su palabra. Palabra que revelada en primer lugar oracularmente, ha sido luego puesta por escrito en los libros que denominamos Escritura ${ }^{20}$. Por estas circunstancias, la teología calvinista, mucho menos kenótica que la de Lutero, le concede desde el inicio más espacio a la razón y al estudio. Así, Calvino no parece haberle otorgado un gran significado a la diferencia entre la palabra oral y la escrita. Para él la Escritura debe ser estudiada cuidadosamente y, con la ayuda del Espíritu, la Palabra de Dios puede alcanzar su objetivo con la fe y la razón trabajando juntamente. Pero esto no atenúa de ningún modo el único principio de autoridad de la sola Scriptura: «Sólo Dios puede dar testimonio de su propia palabra», «la Palabra es el instrumento con el que el Señor dispensa a los fieles la iluminación del Espíritu», las Escrituras «tienen que tener una autoridad completa... tan directamente como si se hubiera oído a Dios hablando en ellas» ${ }^{21}$.

${ }^{19}$ Cfr. BüHLER, P., «Confesiones de fe. B: Tradición protestante», 287.

${ }^{20}$ Lacoste, J.-Y., «Revelación», en Idem (ed.), Diccionario Crítico de Teología, 1058-1064, aquí 1061.

21 CALVINO, J., Institutiones christianae religionis 1,7,1.4 (Opera selecta, hg. von P. BARTH, W. NIESEL y D. SCheuner, 5 Bde., OS, München 1926-1936), (Bd. III, 60-85). Una comparación entre las perspectivas de Lutero, Calvino y Zwinglio, con matices no fáciles de percibir pero con abundante bibliografía orientadora, en Thompson, M. D., «Reformation Perspectives on Scripture: The Written Word of God», The Reformed Theological Review 53/3 (1998) 105-120. 
Este principio de la autoridad de la sola Scriptura llevó a desarrollos impensados en un primer momento. Gadamer, por ejemplo, hizo notar que el origen de la hermenéutica moderna, lo que él denomina la prehistoria de la hermenéutica, está en la necesidad que tuvieron los teólogos protestantes de ofrecer a los predicadores de la Reforma un instrumento que pudiera competir con el principio católico de la tradición invocado en Trento. En efecto, la interpretación de la Escritura en tres pasos -subtilitas intelligendi, subtilitas explicandi, subtilitas applicandi-, con sus reglas racionales, retóricas y psicológicas, podía fundamentar bien el lugar de la certeza en el conocimiento y la aplicación a la vida de la Escritura.

Sin embargo, el embate más fuerte que tuvo que afrontar el principio de la sola Scriptura fue el del racionalismo ilustrado y, después, del historicismo. Es imposible resumirlo en pocas páginas. Pero sí parece necesario recordar dos momentos. El camino de la teología liberal y la crítica bíblica acentuaba de tal manera la distinción entre la razón y la fe que acababa por privar a la Palabra de Dios de un sustento en la Escritura. Así, a Troeltsch, ya en1898, le parecía haber demostrado la absoluta heterogeneidad entre el método teológico y el método histórico, lo que comportaba el abandono de la teología y de todo discurso sobre Dios que no quedara reducido a la filosofía. En una perspectiva menos polémica con sus propios principios protestantes, Harnack llegaba a conclusiones devastadoras en su obra sobre la esencia del cristianismo: allí «Harnack describe la piedad reduciéndola a la nuda relación entre Dios y el alma, entendida además como la sustancia del protestantismo y declarada como esencia del cristianismo; y lo hace de forma tan fascinante, que incluso teólogos y ministros evangélicos luteranos se echaron a temblar ante "la esencia del cristianismo". Harnack había cortado la rama sobre la que ellos mismos estaban sentados. ¿Qué quedaría de la Iglesia una vez quitadas, por motivos espirituales, la cristología, la eclesiología, los sacramentos y el ministerio, declarados ajenos al Evangelio?» ${ }^{22}$.

La teología de la Reforma reaccionó ante estos retos con una nueva fundación en los principios iniciales de la reforma, en la forma de la Teología de la Palabra de Karl Barth, lo que se conoce como la neo-ortodoxia protestante,

22 Dassmann, E., «El "Lehrbuch der Dogmengeschichte" y "Das Wesen des Christentums", de Adolf von Harnack», Anuario de Historia de la Iglesia 13 (2004) 179-198; aquí, 197. Antes de este sumario final, el autor ofrece una exposición clara de los textos de estas dos obras así como de las reacciones que provocaron. 
con posiciones, como la de la Escritura como sedimentación de una tradición oral anterior, más compatibles con principios católicos ${ }^{23}$. También Bultmann, en su reacción, apeló a los principios de Lutero. Aunque sus tesis estaban muy permeabilizadas de prejuicios filosóficos existencialistas, sus discípulos ofrecieron propuestas más fundadas en un análisis histórico que situaba los textos en el contexto de la tradición de la Iglesia primitiva.

Pero, en todo caso, en la óptica protestante sólo el liberalismo podía disolver el principio de la sola Scriptura de la Reforma, y sólo podía disolverlo sin ofrecer nada a cambio. En este sentido, el principio sigue siendo un reto a la interpretación católica.

\section{LA INTERPRETACIÓN CATÓLICA}

La teología católica ha estado marcada por el Magisterio. De hecho, aunque quizás más después de la Reforma, los documentos magisteriales permiten vislumbrar los paradigmas de la teología católica. Es verdad también que el magisterio de la Iglesia católica desde finales del XIX ha tenido muchas veces una formulación netamente teológica: no se limita a declarar, sino que suele argumentar. En todo caso, si evaluamos espontáneamente las etapas en la comprensión de los temas importantes, encontramos enseguida que la caracterización de las épocas se entiende mejor desde el reflejo que tienen en el magisterio que desde otras instancias.

\subsection{Trento y su interpretación}

El movimiento reformador de Alemania parecía exigir la celebración de un concilio en la Iglesia. Tras el fracaso de un entendimiento en la Dieta de Augsburgo (1530) finalmente se convocó; aunque por diversos motivos -guerras entre emperadores, fracasos en las conversaciones- no se inauguró hasta finales de 1545: acudieron sólo los católicos ${ }^{24}$. La primera cuestión que quiso tratar el concilio se refería al procedimiento: el emperador quería empezar por las cuestiones de la reforma, mientras que el Papa prefería que se abordara primero la cuestión doctrinal. Al final se decidió que se abordaran ambas al

${ }^{23}$ Entre otros lugares, pero muy claro, Dulles, A., «Scripture: Recent Protestant and Catholic Views», Theology Today (1980, abril) 7-26.

${ }^{24}$ Sobre estos puntos, Bedouelle, G., «La Réforme catholique», en Bedouelle, G. y Rousell, B., Le Temps des Réformes et la Bible (Bible de tous les temps, n. 5), Paris: Beauchesne, 1989, 329-368. 
mismo tiempo, pero, por una suerte de escrúpulo metodológico, el Concilio comenzó con el Símbolo de la Fe y con el Decreto sobre los libros sagrados y las tradiciones, para que «entiendan, pues, todos por qué orden y camino, después de echado el fundamento de la Confesión de fe, ha de avanzar el concilio y de qué testimonios y auxilios se ha de valer principalmente para confirmar los dogmas y restaurar en la Iglesia las costumbres» (DH 1505).

El Decreto de los libros sagrados y las tradiciones (1546) comienza con una fórmula que tiene sin duda a la vista la terminología y los conceptos de la reforma protestante. El Concilio se propone restaurar en la Iglesia:

«La pureza misma del Evangelio (puritas ipsa Evangelii) que, prometido antes por obra de los profetas en las Escrituras Santas, promulgó primero por su propia boca Nuestro Señor Jesucristo, Hijo de Dios y mandó luego que fuera predicado por ministerio de sus Apóstoles a toda criatura (Mt 28,19s; Mc 16,15) como fuente de toda saludable verdad y de toda disciplina de costumbres; y viendo perfectamente que esta verdad y disciplina se contiene en los libros (in libris) escritos y las tradiciones no escritas (et sine libro traditionibus) que, transmitidas como de mano en mano, han llegado hasta nosotros desde los apóstoles, quienes las recibieron de labios del mismo Cristo, o bien (aut) por inspiración del Espíritu Santo (Spiritu Sancto dictante); siguiendo los ejemplos de los Padres ortodoxos, con igual afecto de piedad e igual reverencia recibe y venera (pari pietatis affectu ac reverentia suscipit et veneratur) todos los libros, así del Antiguo como del Nuevo Testamento, como quiera que un solo Dios es autor de ambos, y también las tradiciones mismas (nec non traditiones ipsas) que pertenecen ora (tum) a la fe ora (tum) a las costumbres, como (vel) oralmente por Cristo o (vel) por el Espíritu Santo dictadas (dictatae) y por continua sucesión conservadas en la Iglesia Católica» (DH 1501).

El Evangelio, término común a los reformadores, se entiende como fuente de toda vida moral. Se presenta en tres fases: en la promesa profética, en la promulgación por parte de Jesucristo y en la predicación apostólica. Se añade después que el Evangelio se testimonia tanto en los libros de la Sagrada Escritura como en las tradiciones no escritas. Este planteamiento corresponde a la propuesta del legado papal, Cervini, que había escrito:

$\ll$ Hay tres principios y fundamentos de nuestra fe: 1. Los libros sagrados que fueron escritos por inspiración del Espíritu Santo. 2. El Evangelio, que nuestro Señor no escribió, sino que lo enseñó oralmente y lo 
plantó en los corazones y del que más tarde tomaron algo los evangelistas, quedando muchas otras cosas confiadas simplemente a los corazones de los fieles. 3. Como el Hijo de Dios no había de permanecer siempre corporalmente con nosotros, envió al Espíritu Santo que revelara en los corazones de los fieles los misterios y enseñara a la Iglesia hasta el fin de los tiempos toda verdad» ${ }^{25}$.

Es claro que las tradiciones a las que se refiere el Concilio, y que algunos padres conciliares ejemplificaban en sus escritos ${ }^{26}$, se refieren, al menos en bastantes ocasiones, a aquellas que la Reforma entendía como abusos. También es verdad que la mayor parte de los padres conciliares estaban convencidos de que el testimonio del Evangelio se encontraba partim ... partim en las Escrituras y en las tradiciones, aunque un grupo de padres conciliares consiguieron que el texto no recogiera estos adverbios sino la fórmula in ... et. Hay, sin embargo, dos interpretaciones distintas del decreto que orientan su recepción en el Concilio Vaticano II.

La teología posterior a Trento, especialmente en un contexto polémico con la teología de la Reforma, entendió estas tradiciones en el sentido material: el contenido del Evangelio está expresado de modo historializado también en las costumbres de la Iglesia que vienen transmitidas junto con la fe (tum ... tum). En ese sentido la teología y la vida de la Iglesia no podían vivir sólo de la Sagrada Escritura. Esta corriente da a luz a la conocida teoría de las dos fuentes, a la inserción del Magisterio como parte de la tradición y como regla inmediata de fe, etc. ${ }^{27}$ Cuando esta posición se quiere hacer compatible con una teoría de la Tradición que acercaba los principios católicos a los principios de la Reforma, algunos autores entendieron que según las actas del Concilio, la expresión, in libris ... et sine libro traditionibus se tenía que interpretar en el sentido de que el Evangelio se expresaba totum en la Escritura y totum en la Tradición ${ }^{28}$.

${ }^{25}$ Cfr. Ratzinger, J., «Interpretación del decreto tridentino sobre la Tradición», en RAHNER, K. y RATZINGER, J., Revelación y Tradición, 55-78; aquí, 57.

26 Cfr. Congar, Y.-M., La tradición y las tradiciones, I, San Sebastián: Dinor, 1964, 273-278.

27 Cfr. Kasper, W., Dogma y Palabra de Dios, Madrid: Razón y Fe, 1969; SesboüÉ, B. y Theobald, C., Historia de los dogmas, IV: La Palabra de Salvación, Salamanca: Secretariado Trinitario, 1997, 107-136.

28 Ésta es la tesis con la que concluye Geiselman, J. R., Sagrada Escritura y Tradición, Barcelona: Herder, 1968, 382, en lo que se refiere a la fe. Frente a estas tesis, escribe RATZINGER, J., «Ensayo sobre el concepto de Tradición» y «Interpretación del decreto tridentino sobre la Tradición», en RAhner, K. y RATZINGER, J., Revelación y Tradición, Barcelona: Herder, 2002 (orig. 1965). 
De esta manera se podía salvar el principio protestante de la suficiencia material de la Escritura, pero a cambio quedaba sin sentido la referencia a la Tradición en Trento. En un nuevo estudio histórico del decreto, Ratzinger vino a mostrar que, incluso con la expresión partim ... partim, no existía ningún problema si el decreto se entendía -como se deduce de las mismas discusiones conciliares- en el sentido pneumatológico propuesto por Cervini y claramente presente en el texto del decreto. Las diversas concepciones de la Tradición presentes en las discusiones están armonizadas en torno al principio penumatológico: «Se pueden verificar en los debates tridentinos cuatro estratos del concepto de tradición: 1. La tradición inscrita, es decir, el Evangelio no sólo en la letra, sino en el corazón. 2. El hablar del Espíritu Santo a lo largo de todo el tiempo de la Iglesia. 3. La actividad conciliar de la Iglesia. 4. La tradición litúrgica y toda la tradición de la vida de la Iglesia. En estas cuatro capas, que hay que tener ante los ojos como trasfondo ideológico del decreto, se expresa la realidad una del presente cristiano en que está a la verdad presente todo el pasado post-apostólico (y que, a la verdad, se remonta ya al tiempo apostólico mismo); el pasado, decimos, post-apostólico de la vida de la Iglesia, en que la Escritura es un elemento central, pero nunca el único» ${ }^{29}$.

\subsection{Dei Verbum}

La Escritura y su interpretación en la Tradición encontraron su asiento en el contexto del Concilio Vaticano II (1965). Hasta entonces, también en el magisterio reciente, se hablaba de la Escritura y de la Tradición como de dos fuentes de la revelación. Con todo, la teología de la Tradición había experimentado un desarrollo -a través de Newman o de la escuela de Tubinga- de modo que ya no se hablaba de tradiciones sino de Tradición ${ }^{30}$. Además, es conocido que las formulaciones de la Tradición en el Vaticano II deben mucho a Congar, uno de los redactores principales, que conocía bien, tanto la tradición católica, como las fuentes patrísticas sobre el tema y los escritos de los re-

29 RATZINGER, J., «Interpretación del decreto tridentino sobre la Tradición», 78. Subrayado mío: parece claro que este hoy de la Tradición es el principio que rige el concepto en Dei Verbum.

30 Para Ratzinger, Dei Verbum es resultado de la confluencia de tres movimientos pujantes de la primera mitad del siglo XX: la nueva reflexión sobre el concepto de tradición, la emergencia del método histórico-crítico en el estudio de las Escrituras y la renovación bíblica. RATZINGER, J., «Einleitung zur Dogmatischen Konstitution über die göttliche Offenbarung», en VORGLIMLER, H. (ed.), Das Zweite Vatikanische Konzil, 498. 
formadores $^{31}$. Los tres años de discusiones en el Concilio aseguran además que la redacción final está muy medida ${ }^{32}$, entre otras cosas porque muchos protagonistas del Concilio veían en el futuro texto una oportunidad en el camino ecuménico.

El primer texto que se presentó para la discusión titulado De fontibus revelationis (1962) seguía la manualística católica y presentaba una doble fuente de revelación, la Escritura y la Tradición ${ }^{33}$ : afirmaba expresamente que algunas verdades sólo se conocían por Tradición a la que, por tanto, había que tener por «constitutiva» ${ }^{34}$. Retirado de la discusión, se presentó un segundo texto titulado De divina revelatione, que no refería ya a las fuentes de la revelación. Pero su silencio sobre la Tradición constitutiva se podría interpretar como una aceptación de la Tradición como meramente «interpretativa» de la Escritura, afirmando, con ello, la «suficiencia material» de la Escritura: es decir, que explícita o implícitamente todo el contenido de la fe está expresado en la Escritura ${ }^{35}$. El texto recibió muchas críticas ${ }^{36} \mathrm{y}$ fue sometido a muchas correcciones antes de ser sometido a discusión pública en el Concilio. Finalmente, los impasses de la discusión encontraron salida con la aparición de un primer capítulo titulado «La re-

${ }^{31}$ Además, en el texto están latentes estudios como los de J. R. Geiselmann o J. A. Möhler; cfr. «La Tradición como viva vox del Evangelio», en GarCía MORALES, J., La inspiración biblica a la luz del principio católico de la tradición: convergencias entre la Dei Verbum y la teología de P. Benoit, O.P., Roma: Pontificia Universitá Gregoriana, 2012, 123-203.

${ }^{32}$ Los comentarios a la constitución (Vorglimler, Höping, etc.) lo muestran, así como la historia de su composición (cfr., por ejemplo, BURIGANA, R., La Bibbia nel concilio. La redazione della costituzione «Dei Verbum» del Vaticano II, Bologna: Il Mulino, 1998). De modo resumido, lo muestro en Balaguer, V., «La Constitución dogmática Dei Verbum», Annuarium Historiae Conciliorum 43/2 (2013) 271-330.

33 SCHELKens, K., Catholic theology of revelation on the eve of Vatican II: a redaction history of the schema «De fontibus revelationis» (1960-1962), Leiden-Boston: Brill, 2010.

${ }^{34}$ Integram revelationem, non in sola Scriptura, sed in Scriptura et Traditione, tanquam in duplici fonte contineri ...... Sacra Scriptura, cum sit inspirata, ad enuntiandas et illustrandas veritates fidei instrumentum praebeat divinum, eius nibilominus sensus nonnisi Traditione apostolica «certe» et «plene» intelligi vel etiam exponi potest; immo Traditio, eaque sola, via est qua quaedam veritates revelatae, eae imprimis quae ad inspirationem, canonicitatem... (Acta synodalia Sacrosancti Concilii Oecumenici Vaticani II, Ciudad del Vaticano: Typis polyglottis Vaticanis, 1970-1986; en adelante, AS con el tomo y las páginas correspondientes; aquí, AS I/3, 14-15).

35 La cuestión no era sólo un escrúpulo teológico, sino que afectaba también a la misma vida de los fieles. Pocos años antes había tenido lugar una discusión no pequeña sobre la «oportunidad» de la proclamación del dogma de la Asunción de María: una verdad que no está atestada en la Sagrada Escritura y cuyos primeros textos explícitos son relativamente tardíos.

36 La ausencia puede verse especialmente en los nn. 8 y 24 del Texto (AS III/3, 782-791). Las críticas enviadas por los padres conciliares -Siri, Carli, Builes, Plures Patres Conciliares, Mazzoldi, Florit, Batanian-, en AS III/3, 800-801, 817-818, 811-812, 918, 889-890, 850, 837, 803. 
velación en sí misma», donde la revelación es descrita en términos de acontecimiento y de salvación, de modo que Escritura y Tradición aparecen por primera vez en el capítulo II, dedicado a la «transmisión de la divina revelación». A partir del capítulo III, el documento conciliar trata exclusivamente de la Sagrada Escritura (1964). Con ligeros retoques en 1965 se aprobó Dei Verbum.

En el capítulo VI de Dei Verbum, el último, es donde aparece la expresión anotada al comienzo de estas páginas: la Sagrada Escritura una cum sacra Traditione es regla de fe y alma, fuerza, vigor, etc., para la vida en la Iglesia (DV 21.24). Esta fórmula es significativa y perfectamente aceptable tanto para el planteamiento de la sola Scriptura de la Reforma como para la Iglesia Romana. Un ejemplo. En el diálogo entre católicos y luteranos en USA, en el volumen dedicado al tema de la Escritura y la Tradición, se apuntan las confluencias entre católicos y luteranos y a continuación se anota que permanecen algunas diferencias de matiz, en concreto, se dice: «Los luteranos mantienen que la Escritura sola es la norma última con la que deben ser juzgadas las tradiciones. Los católicos mantienen que la norma decisiva por la que deben ser juzgadas las tradiciones y las doctrinas es la Escritura junto con la viva tradición apostólica que se perpetúa en la Iglesia mediante el influjo del Espíritu Santo» ${ }^{37}$. Un autor luterano -de manera, obviamente, provocativa- comenta: $\ll$ Si yo, como luterano, tuviera que elegir entre ambas posiciones, incluso si tuviera la posibilidad de aceptar ambas, elegiría la católica como más completa y como una descripción más adecuada del camino por el que los luteranos han procedido clásicamente en teología dogmática, sacramental y litúrgica» ${ }^{38}$.

Por eso, el significado de la expresión se debe encontrar en otro lugar de Dei Verbum, en el capítulo II donde, como se ha dicho, se trata de la transmisión de la revelación, y dentro de ella, de las relaciones entre la Sagrada Escritura y la Tradición. Junto al aspecto dogmático el capítulo transcurre según un modelo también cronológico: de Cristo a los apóstoles, de los apóstoles a sus sucesores y, de ahí a la presencia en la Iglesia ${ }^{39}$. Por eso, a diferencia del

37 Skillrud, H. C., Stafford, J. F. y MarTensen, D. F. (eds.), Scripture and Tradition: Lutherans and Catholics in Dialogue IX, 49-50.

38 Braten, C. E., «A Shared Dilemma. Catholics and Lutherans on the Authority and Interpretation of Scripture», Pro Ecclesia X/1 (2001) 63-75; aquí, 64. De manera no provocativa, H. Schlier exponía su recorrido personal donde el estudio del Nuevo Testamento desde presupuestos estrictamente protestantes le había llevado al camino de la Iglesia católica: SCHLIER, H., «Breve balance», Communio, 19 segunda época (1997) 146-161.

39 De cómo el Antiguo Testamento es concebido aquí, cfr. VARO, F., «El Antiguo Testamento en el Concilio Vaticano II», Scripta Theologica 47 (2015) 155-175. 
capítulo VI, aquí parece que se describen Escritura y Tradición desde el punto de vista de la tradición viva en la Iglesia.

El capítulo se inicia con Jesucristo, en quien tota revelatio consummatur, que manda a los apóstoles a predicar el Evangelium (DV 7). Revelación y Evangelio vinculan este capítulo con el anterior (cfr. DV 2a, 3a, 4a, 6a). Aquí Dei Verbum sigue a Trento, aunque con ligeros cambios nacidos de la nueva orientación de la revelación: personal, dialógica, histórica y sacramental ${ }^{40}$. El segundo párrafo se refiere a la Tradición que va de los apóstoles a sus sucesores: los apóstoles reciben de Cristo y del Espíritu Santo -por eso, la Tradición apostólica se predica después como Palabra de Dios (cfr. DV 9)-, los sucesores de los apóstoles reciben de los apóstoles: por eso, la Tradición eclesiástica sólo transmite la Palabra de Dios.

Los dos números siguientes (DV 8-9) se dedican a la Tradición: en sí misma y en sus relaciones con la Escritura. El Concilio maneja la noción activa de Tradición, subrayando la acción de transmitir: sólo usa «tradiciones», el término de Trento, al citar un texto de san Pablo. La Tradición se describe en su totalidad: la enseñanza, la vida y el culto de la Iglesia. Se subraya así la continuidad en la Iglesia de la Tradición apostólica y la eclesiástica. Para algunos autores, este alargamiento de la Tradición hasta hacerla coextensiva con la vida de la Iglesia, lleva aneja cierta indefinición que además puede difuminar la diferencia sustancial entre Tradición apostólica y postapostólica ${ }^{41}$.

De todas formas, el tema que se quería solventar era el de las relaciones de la Tradición con la Escritura. El Concilio no declaró expresamente una «tradición constitutiva»; en cambio, afirmó que la Tradición recibía la Palabra de Dios de los apóstoles: «La Sagrada Tradición transmite íntegramente a los sucesores de los Apóstoles la Palabra de Dios a ellos confiada por Cristo Señor y por el Espíritu Santo» (DV 9; cfr. 8a). Por tanto, tampoco

${ }^{40}$ Del Evangelio que, según Trento, Cristo ore promulgavit se afirma ahora que Ipse adimplevit et proprio ore promulgavit; la obra de los apóstoles, que en Trento era la predicación, es ahora praedicatione orali, exemplis et institutionibus y nuntium salutis scriptis. Cfr. VANHOYE, A., «La recepción en la Iglesia de la Constitución Dogmática Dei Verbum», en Sánchez Navarro, L. (ed.), Escritura e interpretación. Los fundamentos de la interpretación biblica, Madrid: Palabra, 2004, 147-173; aquí 157-161; más ampliamente, MANSO, A.-C., «Dei Verbum y la tradición crítica hermenéutico-pragmática», Excerpta e Dissertationibus in Sacra Theologia LX/2 (2013) 67-186.

41 FranZINI, A., Tradizione e Scrittura. Il contributo del Concilio Vaticano, Brescia: Morcelliana 1978, 241; SesboüÉ, B. y Theobald, C., Historia de los dogmas, IV: La Palabra de Salvación, 424; IzQuiERdo, C., Parádosis. Estudio sobre la tradición, Pamplona: Eunsa, 2006, 80-90. 
puede entenderse la Tradición como meramente $\ll$ interpretativa ${ }^{42}$. Escritura y Tradición transmiten desde un mismo origen -scaturigo, no fons- la $\mathrm{Pa}-$ labra de Dios de la Tradición apostólica, aunque difieren en el modo de transmitirla.

Ahora bien, la Tradición percibe a la Escritura como algo singular. Percibe que está «inspirada» y que transmite la Palabra de Dios, verbum Dei, siendo Palabra de Dios: locutio Dei (DV 9). Percibe que en ella «la predicación apostólica... está expuesta de un modo especial» (DV 8a). Su percepción de la Escritura como algo singular, que no se diluye en la Tradición, llega al punto de que puede discernir cuáles son exactamente los libros que la componen: el canon integro de los libros sagrados (DV 8c). El entero texto de DV 8, por lo demás, supone una relación sujeto-Tradición vs. objetoEscritura entre las dos. Por esta relación hermenéutica, la Tradición viva (DV 8c) crece en la comprensión de lo transmitido desde los apóstoles (DV 8b), también al comprender mejor la Escritura y al comprenderse la Tradición en ella (DV 8c). Pero es precisamente la singularidad de la Escritura la que hace que no quede confundida con la Tradición: la Escritura es Palabra de Dios siendo una Escritura históricamente determinada. De esto extraerán consecuencias los siguientes capítulos de la constitución. No se dice nada de la «suficiencia material». Lo suficiente está en lo que ab Apostolis traditum est, que encierra todo lo necesario -omnia complectitur- para que el Pueblo de Dios viva santamente. Bastantes comentaristas, con Ratzinger a la cabeza, piensan, sin embargo, que la descripción de la Tradición quizás peca un poco de optimismo, y que se perdió una oportunidad para describir el papel rector de la Escritura ante las deficiencias, posibles e históricamente sucedidas, de la Tradición ${ }^{43}$.

${ }^{42}$ Para reforzar este hecho - probablemente también para contentar a quienes pedían que se aprobara una «mayor amplitud objetiva» de la Tradición- se añadió a última hora esta frase: «pero la Iglesia no obtiene su certeza acerca de todas las verdades reveladas solamente de la Sagrada Escritura» (DV 9). Por otra parte, es indudable que la Tradición es por esencia interpretativa. El texto de Dei Verbum, a pesar de la nueva definición de Tradición, no ha abandonado la idea de las «fuentes» de la revelación. Una explicación como la que sugería Ratzinger -con la Tradición conteniendo en sí la Escritura, como entidad insita en ella, a la que interpreta y a la que tiene también como medida para alcanzar la Palabra de Dios, siempre más grande- hubiera sido probablemente más eficaz. Cfr. SöDING, Th., «El alma de la teología. Su unidad desde el espíritu de la Sagrada Escritura en Dei Verbum y en J. Ratzinger», Communio nueva época 7 (2007) 37-54.

43 Así Ratzinger, J., «Kommentar zur Dogmatischen Konstitution über die göttliche Offenbarung. II. Kapitel», 525. 


\section{CONCLUSIÓN}

Obviamente, hay muchas más cosas en el diálogo abierto por reto de la sola Scriptura originado por Lutero. La cuestión afecta directamente al ejercicio del Magisterio en la Iglesia y aboca al final en cuestiones eclesiológicas y hermenéuticas. Con todo, a día de hoy, la exégesis tanto la católica como la protestante tienen como tarea primera armonizar el sentido teológico del texto -Palabra de Dios en la Iglesia- con el sentido histórico propuesto desde la metodología histórico crítica, que, además, en las expresiones de los exegetas, se propone más de una vez como antagónico del primero. Más arriba se han apuntado algunas respuestas de la Reforma, pero debe reconocerse que esta cuestión parece plantear interrogantes de mayor entidad a la interpretación protestante que a la católica ${ }^{44}$.

La interpretación católica en un primer momento se mantuvo al margen de esta investigación, pero con el Concilio Vaticano II se propuso encarar la «ardua disputa entre la razón moderna y la fe cristiana». Ahora bien, la razón moderna sitúa el problema epistemológico antes que el ontológico: no quiere hablar del ser sin antes poner en claro el alcance y los límites del conocer. Esto supone «definir de modo nuevo la relación entre la fe y las ciencias modernas, ...también a la ciencia histórica» ${ }^{45}$. Según el Cardenal Ratzinger, «una lectura cuidadosa del texto entero de Dei Verbum permite encontrar los elementos esenciales de una síntesis entre el método histórico y la "hermenéutica" teológica. Pero esta armonía no es inmediatamente evidente» ${ }^{46}, \mathrm{y}$ necesita de un trabajo que el mismo Cardenal cifraba, cuando menos, en una generación. En

${ }^{44}$ A este propósito puede ser instructivo recordar un episodio invocado más de una vez por J. Ratzinger: «En la correspondencia de Harnack-Peterson, Peterson, al dar las gracias por el envío que le ha hecho Harnack de "El Antiguo Testamento en las cartas y comunidades paulinas", le escribe que, en sus disquisiciones sobre la escritura y su interpretación, Harnack no había expresado el principio protestante, sino el católico». A lo que replica Harnack: «que el llamado "principio formal" del antiguo protestantismo es una imposibilidad crítica y que frente a él el principio formal católico, que es mejor, constituye una perogrullada; pero, materialmente, el principio católico de tradición devasta más fuertemente la historia (lo mismo como maleza salvaje que sujeto a la podadera del magisterio), aunque afortunadamente el Nuevo Testamento comprende en realidad las mejores fuentes», RAHNER, K. y RATZINGER, J., Revelación y Tradición, 31-32. En relación con el Magisterio, Ratzinger sacaba de este texto valiosas consecuencias: cfr. RATZINGER, J., «Discurso del Emmo. y Revmo. Cardenal Dr. Joseph Ratzinger con motivo del doctorado Honoris causa en la Universidad de Navarra», Scripta Theologica 30 (1998) 387-393.

45 BeNEDICTO XVI, «Allocutio ad Romanam Curiam ob omina natalicia», AAS 98 (2006) 1, 40-53.

${ }^{46}$ Cfr. Ratzinger, J., «La interpretación bíblica en conflicto. Sobre el problema de los fundamentos y la orientación de la exégesis», en SÁNCHEZ NAVARro, L. (ed.), Escritura e interpretación, 25. 
el campo de la epistemología, la hermenéutica filosófica ha mostrado las falsas seguridades en las que se apoya la metodología histórica cuando pretende la exclusividad de la interpretación de los textos del pasado, y con ello reivindica el valor de la experiencia hermenéutica y por tanto el valor epistemológico de la tradición y de la autoridad. El estudio histórico del canon, o de la interpretación en la regla de la fe, muestran que lo que se transmite no es tanto una Escritura como objeto, cuanto una Escritura interpretada ${ }^{47}$. Éstos, entre otros puntos, permiten pensar en que la síntesis anhelada está un poco más cerca.

47 Unas acertadas intuiciones en este punto, en GARCía-TALÓN, S., «La transmisión de los textos como criterio para su interpretación», Scripta Theologica 48 (2016) 9-40. 


\section{Bibliografía}

Balaguer, V., «La Constitución dogmática Dei Verbum», Annuarium Historiae Conciliorum 43/2 (2013) 271-330.

Bedouelle, G., «La Réforme catholique», en Bedouelle, G. y Rousell, B., Le Temps des Réformes et la Bible (Bible de tous les temps, n. 5), Paris: Beauchesne, 1989, 329-368.

BORI, P. C., L'interpretazione infinita. L'esegesi cristiana antica e le sue trasformazioni, Bologna: Il Mulino, 1987.

BraAten, C. E., «A Shared Dilemma. Catholics and Lutherans on the Authority and Interpretation of Scripture», Pro Ecclesia X/1 (2001) 63-75.

BüHLER, P., «Confesiones de fe. B: Tradición protestante», en LaCoste, J.-Y. (ed.), Diccionario Crítico de Teología, Madrid: Akal, 2007, 287-288.

Burigana, R., La Bibbia nel concilio. La redazione della costituzione «Dei Verbum» del Vaticano II, Bologna: Il Mulino, 1998.

Calvino, J., Institutiones christianae religionis 1,7,1.4 (Opera selecta, hg. von P. Barth, W. Niesel y D. Scheuner, 5 Bde., OS, München 1926-1936), (Bd. III, 60-85).

Congar, Y.-M., La tradición y las tradiciones, I, San Sebastián: Dinor, 1964.

Corsani, B., Lutero e la Biblia, Brescia: Queriniana, 2001.

Dassmann, E., «El "Lehrbuch der Dogmengeschichte" y "Das Wesen des Christentums", de Adolf von Harnack», Anuario de Historia de la Iglesia 13 (2004) 179-198.

Dulles, A., «Scripture: Recent Protestant and Catholic Views», Theology Today (1980, abril) 7-26.

EBeLING, G., Evangelische Evangelienauslegung. Eine Untersuchung zu Luthers Hermeneutik, Tübingen: Mohr, 1962.

Elowsky, J., «Scripture and Tradition in an Evangelical Context», Concordia fournal, Winter 2016, 41.

FranZINI, A., Tradizione e Scrittura. Il contributo del Concilio Vaticano, Brescia: Morcelliana, 1978, 241.

García Morales, J., La inspiración biblica a la luz del principio católico de la tradición: convergencias entre la Dei Verbum y la teología de P. Benoit, O.P., Roma: Pontificia Universitá Gregoriana, 2012, 123-203.

GARCía-TALÓN, S., «La transmisión de los textos como criterio para su interpretación», Scripta Theologica 48 (2016) 9-40. 
Geiselman, J. R., Sagrada Escritura y Tradición, Barcelona: Herder, 1968.

IZQuierdo, C., Parádosis. Estudio sobre la tradición, Pamplona: Eunsa, 2006.

Kasper, W., Dogma y Palabra de Dios, Madrid: Razón y Fe, 1969.

Lacoste, J.-Y., «Revelación», en IDEM (ed.), Diccionario Crítico de Teología, Madrid: Akal, 2007, 1058-1064.

Lacoste, J.-Y., «Teología», en Idem (ed.), Diccionario Crítico de Teología, Madrid: Akal, 2007, 1181-1187.

Lazareth, W. H., «Luther's 'Sola Scriptura': Traditions of the Gospel for Norming Christian Righteousness», en Neuhaus, R. J. (ed.), Biblical Interpretation in Crisis: the Ratzinger Conference on Bible and Church, Grand Rapids, Mich.: Eerdmans, 1989, 50-73.

Lutero, M., D. Martin Luthers Werke: Kritische Gesamtausgabe, Weimar: Hermann Böhlaus Nachf-Graz: Academische Druck - und Verlagsanstalt, 1888-2009.

Manso, A.-C., «Dei Verbum y la tradición crítica hermenéutico-pragmática», Excerpta e Dissertationibus in Sacra Theologia LX/2 (2013) 67-186.

MERRICK, J. R. A., «Sola Scriptura and the regula fidei: the Reformation scripture principle and early oral tradition in Martin Chemnitz, Examination of the Council of Trent», Scottish Fournal of Theology 63/3 (2010) 253-271.

O'Callaghan, P., «Sola Scriptura o tota Scriptura? Una riflessione sul principio formale della teologia protestante», en TÁBET, M. (ed.), La Sacra Scrittura anima della teologia, Città del Vaticano: Libreria Editrice Vaticana, 1999, 147-168.

RAHNER, K. y RATZINGer, J., Revelación y Tradición, Barcelona: Herder, 2002.

RAtzinger, J., «Discurso del Emmo. y Revmo. Cardenal Dr. Joseph Ratzinger con motivo del doctorado Honoris causa en la Universidad de Navarra», Scripta Theologica 30 (1998) 387-393.

RATZINGER, J., «Einleitung zur Dogmatischen Konstitution über die göttliche Offenbarung», en Vorglimler, H. (ed.), Das Zweite Vatikanische Konzil. Teil II (Lexikon für Theologie und Kirche), Freiburg-Basel-Wien: Herder, 1967, 498-503.

RatZINGER, J., «Kommentar zur Dogmatischen Konstitution über die göttliche Offenbarung. I Kapitel», en Vorglimler, H. (ed.), Das Zweite Vatikanische Konzil. Teil II (Lexikon für Theologie und Kirche), Freiburg-BaselWien: Herder, 1967, 504-520.

RATZINGER, J., «Kommentar zur Dogmatischen Konstitution über die göttliche Offenbarung. II. Kapitel», en Vorglimler, H. (ed.), Das Zweite Vati- 
kanische Konzil. Teil II (Lexikon für Theologie und Kirche), FreiburgBasel-Wien: Herder, 1967, 521-528.

RATZINGER, J., «La interpretación bíblica en conflicto. Sobre el problema de los fundamentos y la orientación de la exégesis», en SÁNCHEZ NAVARRO, L. (ed.), Escritura e interpretación. Los fundamentos de la interpretación biblica, Madrid: Palabra, 2004, 19-54.

SCHELKENS, K., Catholic theology of revelation on the eve of Vatican II: a redaction bistory of the schema «De fontibus revelationis» (1960-1962), Leiden-Boston: Brill, 2010.

SCHLIER, H., «Breve balance», Communio, 19 segunda época (1997) 146-161.

Sesboüé, B. y Theobald, C., Historia de los dogmas, IV: La Palabra de Salvación, Salamanca: Secretariado Trinitario, 1997.

Skillrud, H. C., Stafford, J. F. y Martensen, D. F. (eds.), Scripture and Tradition: Lutherans and Catholics in Dialogue IX, Minneapolis: Augsburg, 1995.

SöDING, Th., «El alma de la teología. Su unidad desde el espíritu de la Sagrada Escritura en Dei Verbum y en J. Ratzinger», Communio nueva época 7 (2007) 37-54.

Thompson, M. D., «Reformation Perspectives on Scripture: The Written Word of God», The Reformed Theological Review 53/3 (1998) 105-120.

Vanhoye, A., «La recepción en la Iglesia de la Constitución Dogmática Dei Verbum», en SÁNCHEZ NAVARRO, L. (ed.), Escritura e interpretación. Los fundamentos de la interpretación biblica, Madrid: Palabra, 2004, 147-173.

VARO, F., «El Antiguo Testamento en el Concilio Vaticano II», Scripta Theologica 47 (2015) 155-175.

VISCHER, L. (ed.), Textos y documentos de la Comisión «Fe y Constitución» (19101968), Madrid: BAC, 1968. 